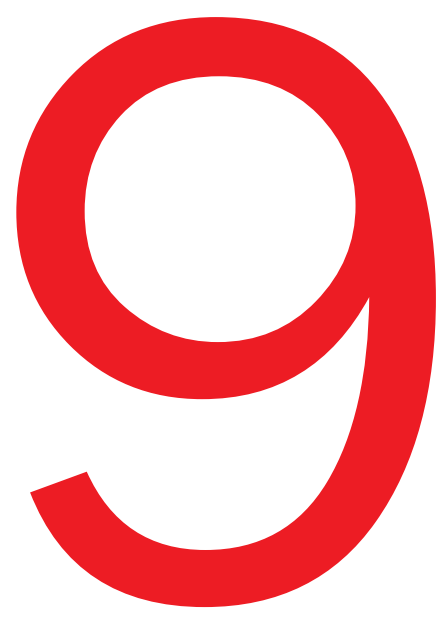

\title{
Abstract
}

The past decade has witnessed increased attention to the benefits of companion animals on human health, though little attention has been paid to the potential to support recovery from a substance use disorder. Amidst an opioid crisis in Canada, studying this overlooked source of support may be beneficial. This study explores how companion animals support the recovery of seven methadone maintenance treatment patients in a Canadian core neighborhood. Through semi-structured interviews and a thematic analysis, the findings demonstrate that individuals' companion animals support their recovery in four areas of their lives: (i) social, (ii) health and wellbeing, (iii) home, and (iv) purpose and empowerment. These themes were found to align with and expand upon the four dimensions of a Life in Recovery outlined by the Substance Abuse and Mental Health Services Administration. Structuring the paper by the expanded categories, this study introduces how companion animals fulfilled supportive roles that other humans could not or chose not to provide, while the human-animal bond encouraged a strengths-based approach to individuals' recovery. This helped foster positive self-identity and a perceived choice over individuals' recovery pathways.

Key words companion animals, methadone maintenance treatment, opioid use disorder, recovery

\section{How Companion Animals Support Recovery from Opioid Use Disorder: An Exploratory Study of Patients in a Methadone Maintenance Treatment Program}

\section{BRYNN M. KOSTENIUK \& COLLEEN ANNE DELL}

\section{Background}

\subsection{Canada's opioid crisis}

Opioid-related deaths have been on the rise across Canada; in 2016 there were 3,014 opioid-related deaths, and 3,988 in 2017.[1] The latest data from the Public Health Agency[1] reports that 3,286 apparent opioid-related deaths occurred between January and September 2018 alone, 93\% of which were unintentional. One contributing factor is the high rate of misused[2] and diverted[3] prescription opioids,[4] although the increasing overdose rate (at present) appears to be disproportionately attributable to highly potent or contaminated street supplies.[5] For example, between January and September 2018, 73\% of accidental apparent opioid-related deaths involved fentanyl or fentanyl analogues. [1]

Between 2016-18, Saskatchewan's proportion of accidental opioid-related deaths involving fentanyl increased from 11\% to $44 \%$,[1] and the province's largest city, Saskatoon, had the second highest hospitalization rate for opioid poisoning among the prairie cities in 2016-17.[6] Most recently, in November 2018 there were nine overdoses alone in the Saskatoon Correctional Centre due to fentanyl-laced substances.[7] Saskatchewan's mortality rate $(7.7$ per 100,000$)$ is, however, lower in comparison to more highly populated provinces like British Columbia, Alberta, and Ontario; 30.9, 19.0, and 9.6 rate per 100,000, respectively.[1] 


\subsection{Methadone maintenance treatment}

Methadone is a controlled substance under Canada's Controlled Drugs and Substances Act and the Narcotic Control Regulations,[8] and is used in Methadone Maintenance Treatment (MMT) to treat longstanding opioid use disorder. $[9,10]$ As a form of harm reduction,[11] MMT is frequently perceived by the general public as a substitute for opioid misuse rather than a method of supporting individuals seeking recovery.[12] MMT involves the prescribing of methadone to prevent withdrawal, decrease craving, and block euphoria, in conjunction with counselling and other supportive services. [10] In fact, it is well-documented that MMT is a treatment that positively impacts individuals' quality of life (e.g., stable employment), social functioning (e.g., contact with care providers), physical and mental health (e.g., avoid harmful street supply drugs), and pregnancy outcomes.[13] It is also an effective means to establishing connections to nonpharmacological support (e.g., counselling).[14]

However, MMT patients commonly face self- and externallyimposed stigma, shame, and discrimination due to their opioid use disorder.[12,15] The addictions field is burdened with areas identified for individuals to improve within, contributing to their diminished self-esteem and perceived lack of control. [15] This is frequently compounded by inequitable living conditions, including poverty, social exclusion, and food insecurity.[16] High rates of co-occurring mental health issues and bloodborne diseases are also found among this population.[16-19] Saskatchewan has the highest diagnosis rate of HIV per capita in Canada, and unlike any other province or territory, injection drug use is the primary mode of transmission.[20,21] Combining these factors, the likelihood of MMT patients securing helpful and appropriate support for their opioid use disorder in Saskatchewan is diminished. Indeed, access to and quality of harm reduction care, including MMT, has been shown to worsen with socioeconomic marginalization.[16]

\subsection{Health benefits of companion animals}

Companion animals have documented benefits to human health, referred to as zooeyia.[22] In Canada, approximately $57 \%$ of households live with at least one companion animal (commonly called pets).[23] Companion animals can enhance feelings of happiness, safety, and self-esteem, decrease feelings of loneliness, and serve as a confidant.[24,25] They can also promote healthy behaviors (e.g., physical activity) and provide a space for social interactions (e.g., conversations at a dog park).[22,26] Additionally, they can help reduce anxiety, heart rate, and blood pressure, decrease the stress hormone cortisol, and increase the feel-good hormone oxytocin.[27-31] There is also related research supporting the beneficial role of pets in addressing mental health and illness.[32-35]

Companion animals have also been identified as an inspiration in some harm reduction approaches to substance use. For example, fear of exposing one's companion animal to second hand smoke can prompt individuals who typically smoke in their residence to smoke outdoors, and even stop smoking altogether.[22] Similarly, a study of street-involved youth in Ottawa by Lem et al.[36] concluded that having a companion animal decreased individuals' drug use by reducing the amount consumed and by transitioning to less harmful drug types. Participants explained that this was partly because they were choosing their pet's welfare over their own personal needs. In the same way, among adults living in homelessness, Irvine[37 p3] found that companion animals can help individuals 'from lapsing into risky behaviours', largely due to feelings of responsibility.

In a review of animal assisted therapy in the treatment of substance use disorders, it was found that animals (dogs and horses) promoted personal change in individuals, offered unconditional love and support, and advanced a sense of connection.[38] Likewise, a study of a MMT program in Saskatoon with a therapy dog found that a beneficial connection was formed between the patient and visiting therapy dog, and that this encouraged MMT program attendance, motivation, and engagement.[39] This human-animal relationship, or bond, specifically addresses the disconnection frequently experienced among individuals who problematically use substances,[40,41] as the bond can provide 'unconditional love, security, trust, and attention'.[42 p6]

\subsection{Support in recovery from opioid use disorder}

In 2012 the Substance Abuse and Mental Health Services Administration (SAMHSA) in the United States Department of Health and Human Services proposed a working definition of recovery from substance use disorders and/or mental disorders: 'A process of change through which individuals improve their health and wellness, live a self-directed life, and strive to reach their full potential'.[43 p3] SAMHSA also developed four dimensions that support a life in recovery: (i) health, (ii) home, (iii) purpose, and (iv) community. SAMHSA has not yet explicitly identified the human-animal relationship as a potential source of support.

Much like SAMHSA, the Canadian Centre on Substance Use and Addiction (CCSA) has also derived six principles of recovery: (i) there are many pathways in recovery, (ii) recovery 
requires collaboration, (iii) recovery is a personal journey toward well-being, (iv) recovery extends beyond the individual, (v) recovery is multidimensional, and (vi) recovery involves everyone.[44] In 2017 the CCSA explored these principles further and asked Canadians about the role of companion animals in their recovery in the first national survey - Life in Recovery From Addiction in Canada - on this topic area. It was found that $88 \%$ of participants identified their relationship with animals or pets as an important support in their recovery, and $44 \%$ found their relationship with animals or pets to help in continuing their recovery.[45]

Recognizing the multidimensionality of recovery, the CCSA supports the development of pet friendly policies and providing opportunities for connecting with therapy animals.[45] In fact, there has been a general increase over the past several years in the incorporation of animals into addictions recovery practice (e.g., therapy dogs at Hazelden Betty Ford treatment centres, animal friendly addiction treatment centres). However, there is an absence of corresponding empirical literature,[46-50] and it is curious whether other institutions, including SAMHSA, could potentially adopt similar mandates involving companion animals.

\subsection{Purpose of study}

Amidst the current opioid crisis across Canada, federal and provincial government bodies have been decreasing barriers to harm reduction measures, including access to takehome naloxone kits, opioid agonist therapy, and supervised consumption sites. Saskatchewan has also added suboxone to its drug formulary (a list of publicly funded pharmaceuticals), which is a safer alternative to methadone and with fewer side effects.[51] However, the potential role of companion animals has been largely overlooked. Considering the known benefits of companion animals to human health, including therapy dogs facilitating treatment of substance use disorders, it is reasonable to consider the role of companion animals in recovery from opioid use disorder. Specifically, the question of how MMT patients' relationships with companion animals can potentially support their recovery from opioid use disorder is nearly unexplored.

Accordingly, seven interviews were undertaken with MMT patients of the Opioid Assisted Recovery Services (OARS) program in Saskatoon, Saskatchewan, Canada for this exploratory study. Being that the project recruited patients who could discuss the role of their companion animal(s) in their recovery, it was likely that those who responded to the call would identify their companion animal as predominantly supportive. Consequently, this study focussed on understanding how companion animals contributed to participants' recovery from opioid use disorder.

\section{Materials and methods}

\subsection{Ethical approval}

This study was reviewed and approved by the University of Saskatchewan Human Behavioural Research Ethics Board in Saskatoon.

\subsection{Participants and recruitment}

Purposeful sampling was used, with OARS patients recruited via poster advertisements within the program's building. OARS counsellors assisted with recruitment by distributing flyers of the poster to patients whom they knew had companion animals. The posters and flyers indicated that the study was exploring how participants' pets might be supports to them in their recovery. The first seven patients to express interest were chosen to participate and one remaining patient who presented himself after the deadline was placed on a waiting list. Drawing on the work of Hagaman and Wutich,[52 p23], "16 or fewer interviews [are] enough to identify common themes from sites with relatively homogeneous groups". Seven interviews were sufficient considering the exploratory nature of this study, and to achieve data saturation given its highly specific aim and setting.

Alias names were created for the four participating men (three Indigenous, one Caucasian) and three women (two Indigenous, one Caucasian) using a random name generator on the internet (Abigail, David, Emily, Emma, Michael, Olivia, Robert). Pseudonyms were also created for their current companion animals by browsing the Saskatoon Society for the Prevention of Cruelty to Animals (SPCA) website. All participants had at least one companion animal at the time of the interview. Abigail and Emily each had one cat while David had two. Michael and Emma each had two dogs, and Robert and his partner Olivia had one cat and one dog. In addition, five of the participants grew up with animals, one did not, and one did not specify. When memories of past pets surfaced in the interviews, participants often elaborated about their experiences with these animals and their roles in the participants' lives.

MMT program patients are diagnosed with an opioid use disorder according to the Diagnostic and Statistical Manual of Mental Disorders, Fifth Edition (DSM-5).[53] All participants in this study had begun their journey to recovery in individualised ways, but common among them was an acknowledgement of their substance use disorder and a desire to overcome 
and/or manage it. The seven study participants had been prescribed methadone by an MMT program physician at the time of their interview, and one participant shared that she was concurrently attempting to 'wean off' of other opioids. One participant disclosed that he was currently using other types of substances, including alcohol and tobacco, while two participants specified that they no longer used additional substances, but had in the past while prescribed methadone. Six of the seven participants reported that they developed their opioid dependency through access to an illegal supply and one via her opioid prescription for pain management. All of the participants were MMT patients, because as indicated previously, suboxone was only recently added to the Saskatchewan formulary in 2017 , and so these patients had minimal opportunity to be prescribed it.

It is also important to acknowledge the characteristics of the neighbourhood that the OARS program is located in and in which all participants reside. OARS is situated in the core area of the inner-city neighbourhood of Riversdale in Saskatoon. This community has a high level of poverty, unemployment, and substandard housing.[54] Less than a decade ago, Riversdale had one of the highest rates of neighbourhood crime in Canada.[55] This is slowly changing as gentrification of the area has begun.[56] A concern with this is further social and physical dislocation of impoverished individuals residing in the neighbourhood and intensifying tension with incoming businesses (e.g., increased police contact for loitering, etc.). Although no participants in this study were homeless at the time of the interviews (some had been in the past), meeting rent and food needs were challenging for most, as social assistance and/or inconsistent income were common (e.g., not being able to work daily). Several participants also discussed difficulty in finding a job while adhering to MMT programming; for example, employers viewed the daily dosing schedule as disruptive to work schedules.

\subsection{Data generation}

The study was designed as a qualitative project,[57] and was conducted in parallel with the interpretivist paradigm, the relativist ontology, and the subjectivist epistemology. Together, these lenses support the research question, which is interested in subjective meanings and experiences.[58,59] It was also assumed that knowledge is co-created by the researcher and the participant through the interview process. To address this notion and to ensure rigour, the researchers actively engaged in reflexivity with one another, as well as through external peer debriefing. Field notes and audit trails were also used throughout.

For the interviews, the OARS office was chosen as an appropriate location because of its convenience and comfort for the participants. The interviews were held in a private room where counselling commonly occurs, and confidentiality is ensured. Eleven questions, drawn from the available literature, were asked in a semi-structured interview format (Table 1). On average, the interviews were $\mathbf{3 0}$ minutes in duration, and were audio recorded then transcribed verbatim. Participants were provided with a $\$ 25$ gift card at the interview in appreciation of their time. Following the interviews, all participants were offered the opportunity to meet with an OARS counsellor for

Table 1: Interview Questions

What kind of pet(s) do you have?

How would you describe your relationship with your pet?

If you could describe how your pet supports you using three words, what would those words be?

Do you feel a sense of responsibility for your pet?

Have there been any times you felt loved by your pet?

Do you feel that you can trust your pet? Depend on them?

How would you compare your relationship with your pet in comparison to relationships with other people?

Do you feel that your pet plays an overall supportive role for you in your recovery? Or through rough patches?

Are there any ways your pet has not helped you in your recovery?

Do you think having a pet would help other people who are trying to recover from substance use?

Is there anything else you would like to share about your pet or your relationship with your pet, related to your recovery? 
debriefing, although none did.

\subsection{Thematic analysis}

A thematic analysis was employed with the assistance of NVivo. Commonalities and differences were analyzed by examining across the data sets (interviews) for free forming, dominant key words and ideas. Specifically, Braun and Clarke's[60] thematic technique guided the analysis, as follows: 1) data was transcribed and re-read numerous times so that the data became very familiar, 2) line by line coding was used to generate initial codes, 3) preliminary, potential themes were generated by clustering codes based on similarity, 4) the themes and codes were then refined and reviewed repeatedly, which included producing multiple thematic maps, 5) themes were then refined further and defined until the analysis accurately represented the data, and 6) quotes and specific examples were then selected to exemplify support for the themes in this paper.

Given the absence of prior research, there were no predetermined themes (the SAMHSA dimensions were identified following the generation of preliminary themes). To generate themes, some level of interpretation was required, and therefore a latent content approach was utilized.[59] Overall, '[t]he goal [was] to develop themes that can be used to describe the experience from the perspective of those that lived it'.[61 para5]

\section{Results}

Through data analysis, common themes of how companion animals support recovery among participants were found.
Specifically, four primary themes with two sub-themes each were abstracted from the data (Figure 1). The first primary theme is 'social', with the two sub-themes of 'emotional support' and 'family' identified as key domains in which companion animals supported recovery among participants. The second primary theme is 'health and well-being', with 'prevention' and 'a reason for recovery' as two sub-themes. The third primary theme is 'home', supported by the two subthemes of 'protection and safety' and 'stability'. The fourth primary theme is 'purpose and empowerment', supported by the two sub-themes of 'responsibility' and 'passion and involvement'.

Overall, individuals' relationships with their companion animals fulfilled supportive roles that other humans could not or chose not to provide. The human-animal bond encouraged a strengths-based approach to individuals' recovery, meaning that focus was placed by individuals on celebrating their strengths and achievements, rather than perceived flaws which are oftentimes emphasized with a substance use disorder. This strengths-based approach influenced a positive sense of self-identity in individuals and enhanced their perception of having choices over their recovery pathway.

\subsection{Theme 1: Social}

Participants identified their relationships with their companion animals as near analogous (and in some cases superior) to their relationships with humans. Companion animals served as a form of emotional support, acting as a confidant during stressful times, and a consistent source of unconditional love and acceptance. Companion animals were also identified as family, which promoted a sense of belonging. All findings

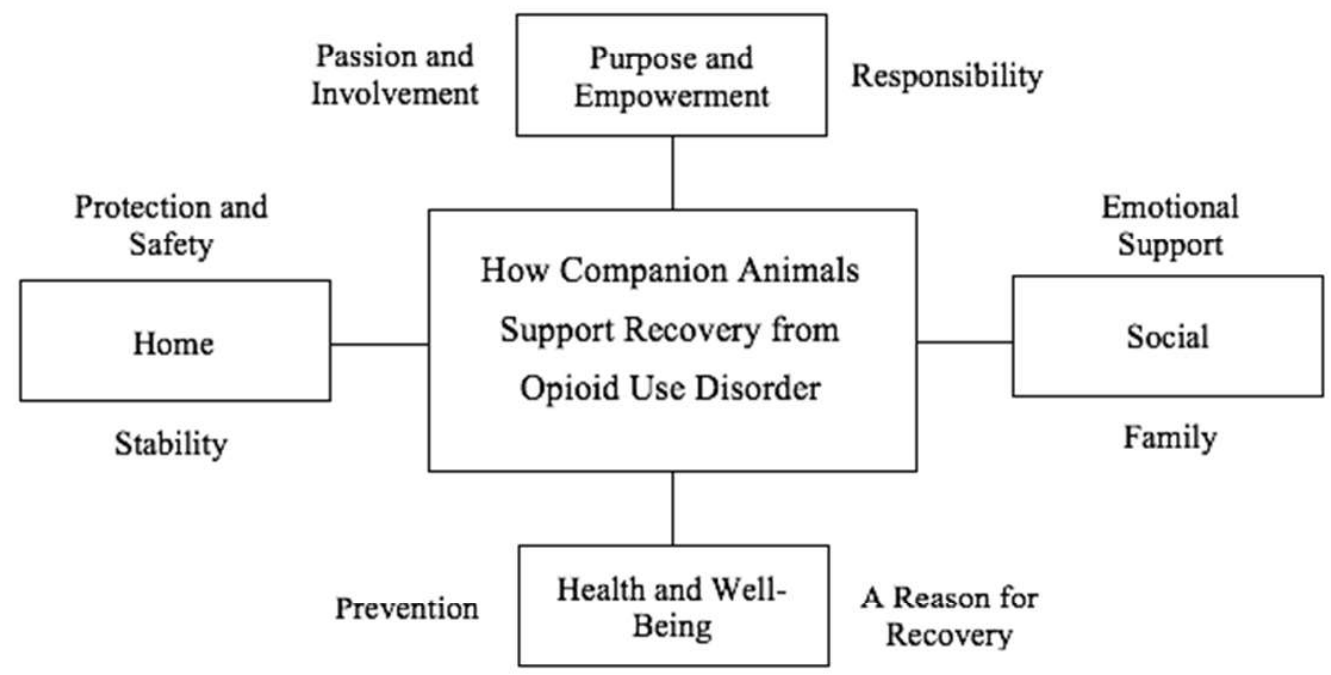

Figure 1: How Companion Animals Support Recovery from Opioid Use Disorder 
within this theme were common among cat and dog owners.

\subsubsection{Emotional support.}

Participants frequently confided in their companion animals and valued their pet's ability to offer unconditional love. These were identified as important to participants' recovery.

\subsubsection{Confidant}

Most participants viewed their companion animal as a confidant they could talk to and with whom they could express raw emotions. Participants valued that their pet simply listened when they needed an outlet, especially when they were not seeking advice or feedback. Michael expressed this in his interview:

Everyone should get an animal for their recovery process. You go to AA [Alcoholics Anonymous] groups, you can't say everything you want in those places. . . Somebody's always opinionated. Somebody's got something to say. Like you don't need, sometimes you don't want anybody to say anything to you, you just want to vocalize your thoughts ... When you have a dog, and you can talk for an hour or two hours or whatever, you sit there and you're with your animals.

A few participants valued how their pet did not pressure them to talk about their feelings, which also aided them in their recovery. Abigail shared:

In some ways it is nice because they don't talk [laughs]. So, you don't have to, or I mean they don't nag. They don't complain you know. Sometimes people tend to put pressure on you. You know. The people who love you don't understand the addiction process, you know I don't even understand it half the time ... my husband doesn't understand and that's the closest person to me.

For participants who had close connections with people around them, like Abigail, participants said they sometimes placed more trust in their companion animal. For others, their companion animal was their primary confidant.

\subsubsection{Unconditional love.}

All seven participants viewed their companion animal as a source of unconditional love. This was identified through what the participants' perceived as acceptance, continuous dependability, and perceived loyalty from the animal. Whenever Robert experienced rough patches, he perceived his dogs to be there for him, which Robert identified as being unconditional love:

It doesn't matter what happens like they just love me no matter what I do or whatever, they love me. They love me no matter what if I'm a bit grouchy or mad some day or kind of get aggressively angry or something, they're still going to love me no matter what . . Y You

know, unconditionally. They love me no matter what.

Like Robert, having a source of unconditional love was expressed by the rest of the participants as helping them to permit self-acceptance. As Abigail said, 'They just accept what you are that day, and you know, and you don't have to go into a big explanation for everything. So, but that's what's nice, is when you're accepted... you know they never left'.

\subsubsection{Family.}

All seven participants referred to their companion animal as family, and six referred to their pet as their child. Being that most participants did not currently have children of their own in their care, this sense of family allowed them to take on the role of a primary caregiver. As Emily shared:

They [my cats] are my responsibility so, I do fully take care of them pretty good, feeding them all the time, stuff like that. But yeah, give them a bath, yeah. They're expensive, but I go out of my way to feed them right.

Or in Robert's words:

I tuck them into bed and I say goodnight to them, I pet them, I reach down and I *pretends to pet animal* and I pet them on the head, 'Goodnight my boy'. And you know, they're my kids! [My partner] can't have babies, like we never had kids together so they're our babies, you know.

Engaging in this familial role appeared to help participants acknowledge their strengths as they boasted when they talked about caring for their pets. A few participants also discussed that this feeling of competence (e.g., as a caregiver) was hard to come by because of experiences associated with their problematic substance use. Robert continued, 'They just give me a new perspective on loving and giving love to something that needs love as much as I did, you know'.

\subsection{Theme 2: Health and well-being}

Companion animals took on a preventative role in participants' recovery processes; they were reported to respond intuitively to individuals' distress by providing comfort (primarily physically). They also stimulated joy and laughter, which often decreased participants' need to use substances by improving their emotional state. Participants also reported that their companion animal gave them a reason for their recovery, and as such encouraged sobriety, a healthier lifestyle, and longevity.

\subsubsection{Prevention.}

Despite being at different stages in their recovery, most participants described how their pet played an important 
preventative role in their recovery.

\subsubsection{Intuition}

Nearly all participants reported that their companion animal 'just knew' when they needed reassurance and comforted them during these times. 'They just know that there's something wrong with you, like emotionally', Michael said, 'you know they just come up to you and they're there to support you'. Similarly, David shared:

I believe animals know, they can pick that up, they sense how you're feeling kind of? And they will, if you're really sad or hurt, they will often come to you, eh. They'll come to you and they picked up that feeling, and they'll come and kind of comfort you. They're good at that sense of feelings.

Although the companion animals had never received formal training, participants discussed the animal's ability to sense when they were upset and in turn respond with what they perceived to be support. For many, this interaction took their mind off of using substances. When participants were distressed and tempted to use substances, their companion animals often responded by calming and comforting them, primarily through physical touch. In Michael's words:

When I'm feeling really down and I want to go back and I'm thinking like this is, one more time and whatever, and they're there to say 'No, no dad you can't do that', you know. They're nuzzling, in your arm or on your arm and ... they're pawing at you and they're getting right in your face you know, saying you can't.

However, in Emma's experience this was not always the case. She described how Bear's (her dog) attitude would change dramatically whenever she was drinking:

... They know right from wrong. If they know you're doing something wrong, they'll let you know and they'll let you know if they don't like it. A lot of times l've noticed Bear, when I'm drinking she'll stay away from me, she won't come to me. And right there, that hurts eh, because she's supposed to love me no matter what you know. But she don't do that, so.

When asked if she perceived this as Bear being judgmental, Emma seemed to attribute Bear's reaction to her own history of abuse as a canine:

She probably had people that were drinkin' and mean on her, because like, I swear she's been abused so many times because of the way she is. Like, you can tell she's got little marks on her head, yeah, she's like scared all the time, like scared ... . if she's feelin' bad she'll let you know. If she's sick she'll let you know. Like a child.

3.2.1.2 Positivity.
Some participants expressed that their companion animal brightened their day by stimulating joy and laughter. This was found for both dog and cat owners. Emily explained:

On rough days ... she brings my spirits up! She's a really loving cat, my spirits are always up when I'm around her all the time ... my day's always so positive when I'm around her... she was there for me all the time! And I was going through hard times. She always brought my spirits up all the time. It didn't matter if I was down, l'd forget about everything and it would always be her, just her.

These interactions with companion animals decreased the participants' stress by fostering feelings of relaxation and happiness. In Abigail's words:

Yeah I feel if I had a bad day or something, you know they just have a way, just you know. When they come near you as they start purring or they just do funny things so you have to laugh. You have no choice but it just kind of distracts you.

By cheering them up during emotional times, companion animals were identified as helping participants divert attention away from their negative emotions. For some, this too helped suppress the need to use substances in that moment.

\subsubsection{A reason for recovery.}

The majority of participants claimed that their companion animal motivated them to continue in their recovery process and attempt to maintain abstinence from other substances. Participants also aspired to live a healthier lifestyle and to live a longer life for the sake of their companion animals.

\subsubsection{Sobriety}

Some participants shared that their companion animals gave them a reason to begin their recovery, particularly by abstaining from using substances. As Robert said:

... I needed to quit and [they] made me realize that my responsibilities and my love and my calm[ness] . . . a person that keeps them, loves them. I can't be that person when I'm addicted and using and stuff because I become an angry, abusive person, that they don't want you know ... They give me a reason to live, for them, to live for myself, and to live for my family, and you know, change. Like I'm not abusive. I'm a different person.

Likewise, Michael's dogs served as a constant reminder for him to maintain his recovery. This story was common, as participants like Michael described how their pets were an important reason to manage their substance use:

Yeah and they're there and they're looking at you, like 'What about us, what's going to happen to us?' 
... It doesn't matter how strong minded you are . . . you're going to forget about everything and go back to your old lifestyle, how you were before your recovery and everything like that. Everybody that is in recovery should have an animal.

\subsubsection{Lifestyle and longevity.}

It was evident that participants' relationships with their companion animals encouraged an overall healthier lifestyle. For some, this meant cessation of opioids and other substances, such as alcohol or tobacco (as described previously). For others, this meant living a more active lifestyle (e.g., walking their dog). For example, Robert explained:

. . . Being healthy and going out and walking our dogs and doing things to extend our lives, if we're not healthy and something happens to us, our animals are going to be left without anybody ... and I quit smoking I haven't smoked for almost a year now too. I just said to hell with it, I just got tired of and you know I struggled with it. It's the same with addictions and crystal meth, and down, and opiates and that. I just quit everything... they [the animals] brought me up to the point where I needed to quit.

Like Robert, other participants expressed worry about not being there for their pet if they were to overdose or pass away at an early age. For David, he felt that this accountability for his cat helped him, because his cat needed him on a daily basis:

They make me be reliable[,] right. I have to go home every day right, you know, l'll go to work sometimes or I'll be out all day but I have to go back. It's like, I don't like to leave them alone more than eight, ten hours you know go back feed them, take after them ... you don't want to have a pet and then turn up in jail or going off and relapsing, not coming home, and you know. The cat needs you to be there, right.

Brett and Michael both mentioned that because pets have a limited lifespan, they felt especially obligated to give them the life they deserve and help them develop to their fullest in the time available.

\subsection{Theme 3: Home}

Companion animals were identified by participants as providing physical protection and psychological safety (specific to dogs only), which offered them increased peace of mind and decreased their anxiety. Companion animals also contributed to their feelings of stability, as participants could depend on coming home to their pet. However, nearly all participants worried about the welfare of their pets.

\subsubsection{Protection and safety.}

Two participants expressed concern for their own safety because of their neighbourhood surroundings and explained how their companion animal helped them to feel safe. Their animals contributed to both their physical and psychological feelings of safety, which in turn helped decrease stress and anxiety for them. Both participants that reported this were dog owners, and so in these cases the species of animal was important. Emma, an owner of two companion dogs, explained:

They really actually saved our, pretty much our asses, because when we were living in an apartment, there used to be a lot of people trying to come kick open our door because they thought it was a drug dealer living there. And so that's why we got the other [second] dog ... If she don't like somebody[,] she'll let them know boy. And they get scared away so ... Now when people come to the door, oh my girls [dogs] just flip right out. So that's a good thing, I'm glad they do that. Because then people you know, 'ooh shit[,] they got dogs!' You know so that is a good thing.

For Michael, having his dog with him in public contributed to feeling safe: 'They even guard you[.] [T]hey even look out for you when you're out walking'.

However, participants also shared that they worried about the safety of their animals (both cats and dogs), and most discussed animal welfare concerns within their Riversdale neighbourhood. A common concern was that animals were stolen for the purpose of being sold for financial gain or for a posted reward. For example, Emily's cat's kittens were stolen from her shortly before her interview for this study:

I didn't have a place so I didn't want to stay there [where her cats got stolen from] because of what happened... I've got a stable place [now] and l've got, I don't have to leave that place and like there's a lock on the door I can lock it and she's [the mother cat] safe so.

Although unfortunate, this event motivated Emily to secure safer living accommodation for her remaining cats. This likely indirectly contributed to her own safety.

\subsubsection{Stability.}

Having a companion animal to come home to daily provided a physical and psychological sense of stability and dependability to the participants. In Brett's words,

They [my cats] need me there right. So yeah, they're a good influence in that way ... I'm back [home] and they're just pretty stable and stuff hey. They're kind of always there, right'.

Michael had similar experiences with his dog, Lily:

Yeah, I had Lily, [she] was like, she was everything to me hey, she was. When I raked the yard, she would 
hide in the leaves. She would bounce out eh... there's a few times where I went to work, and I came back and somebody let her go from the gate... well she just went to the steps and waited on the steps, waiting for me to come home. After eight hours you'd think a dog would run away and do something else ... But she just sat there eh.

Companion animals did not problematically impact housing options for participants in this study. Only one participant (Abigail) expressed frustration regarding how costly damage deposits were for housing dogs in rental accommodations, but she said she accepted this responsibility. She felt that it was worth it and so she always made sure she had enough money to cover the cost.

\subsection{Theme 4: Purpose and empowerment}

Participants took satisfaction, and possibly pride, in the responsibility they showed by allocating a portion of their earnings to care for their companion animal. They also shared passionate stories of animal activism, which appeared to be a source of purpose and empowerment for them.

\subsubsection{Responsibility.}

All of the participants felt responsible for their companion animals. For many, this was largely a financial matter. Specifically, it seemed that the ability to allocate a portion of their income for their animals was associated with a sense of responsibility and autonomy. For example, as David said:

Yeah like they get fed before I do sort of thing, [be]cause they don't have any options, right. You know when you have a pet it's your responsibility. It's a big thing I think. That kind of helps like with addiction and like, you know they get you out of yourself so you're thinking about something other than yourself . . . My money is budgeted for them, I always make sure they have their food . . . they never go without. If I've got two days left of food I go out and get another big bag. They always have treats, they always, everything. Theirs is the top of the list for shopping. Their food is first because they can't do it on their own.

All seven participants also expressed that the costs associated with caring for their companion animals were generally not an issue. When we asked Abigail about this, she responded:

No, I don't find it is! Well, and the thing is when you consider people buy things for themselves that are pretty wasteful you know, [like] gambling, and then you complain that you have to buy cat food or cat litter?

\subsubsection{Passion and involvement.}

Six of the seven participants rescued their pets from potentially harmful environments. Many participants viewed this aspect of their pet's life as relatable, and it was for this reason that they felt the need to 'save their animals.' In Emma's words:

I know how it feels to be abandoned, I know how it feels to be hurt, hit, raped, whatever, you know because l've been there and l've never had an animal growing up in my life or when I went through all this but now that I do, I feel what they feel, you know? So that's pretty much what opened up my heart more was my dogs.

For a few participants, rescuing animals had become a passion, so much so that they identified this role as one of their most defining characteristics. For example, Michael identified himself as an animal activist. He rescued his first dog when she was a puppy and was being dragged down a snowy street, and his other dog from being kenneled in a small, windowless basement room. Michael also shared how he contacts animal control whenever he witnesses potential animal abuse, and how he broke a car window to rescue a dog from the heat on a summer day (the police acknowledged animal maltreatment had occurred).

\section{Discussion}

Following data analysis, it was found that the preliminary themes fit into and/or aligned with, and expanded upon the four dimensions that promote a life in recovery outlined by SAMHSA: community, health, home, and purpose.43 However, most of the categories that emerged in this study are termed differently from the SAMHSA categories (social instead of community; health and well-being in place of health; home in both instances; and purpose and empowerment in place of purpose). These terms reflect the findings more accurately than the SAMHSA categories, perhaps because the original SAMHSA terms were derived to describe relationships with other humans. As such, a supplementary understanding of support throughout recovery from opioid dependency is offered, although there is great alliance with the SAMHSA dimensions. Given this overlap, the well-established SAMHSA categories are referred to in the framing of the discussion below in relation to our expanded categories, as we describe how companion animals are a unique and complementary form of support.

\subsection{Theme 1: Social}

SAMHSA[43 p3] identifies community (termed social in the current study) as one of the four major dimensions that support a life in recovery, defined as having relationships and social networks that provide support, friendship, love and hope'. The findings from this study focus on companion animals as a source of emotional support, with attention to 
a sense of familial belonging, including mutual caretaking. The term 'social' was used rather than 'community' due to the singular relationship shared between participants and companion animals, as opposed to relationships between/ among people, as connoted by the term 'community'. Also, although SAMHSA identifies caretaking under the theme 'purpose', caretaking emerged with social importance in this study, with participants' focus on a sense of belonging.

Individuals in recovery from addictions are frequently identified as having a flawed character,[62] and close supports, such as family members, often 'give up' on these individuals because of their perceived lack of commitment and progress in recovery. [63] Unique to individuals' relationships with companion animals is that the animals were perceived to be unconditional, trusting, accepting, and consistent in the emotional support they provided. Animals, and in particular dogs, are socially identified as being non-judgemental and unconditionally loving. Likewise, some respondents seemed to suggest that their companion animals had a better sense of their emotional well-being than humans in their lives. This is supported in the literature; a companion animal can more easily be a confidant, particularly when the fear of judgement and reprisal prevents an individual from expressing their feelings or thoughts. $[24,36]$ This may be partly because emotional and social processing among animals is less complex in comparison to humans,[24] with animals perceived to more easily provide a sense of understanding and acceptance, as well as effortless unconditional love.[24,34,36,64,65] Similarly, one study found that participants felt more secure in relationships with their pets when compared with the attachment security experienced in romantic relationships,[64] while another recent study involving a recovery program concluded that individuals' relationships with their companion animals supported their recovery journey.[66]

However, in the current study one negative case emerged when Emma noted that her dog was upset by her substance use. However, rather than feeling judged by this reaction, Emma expressed empathy for her dog. Much like her dog, Emma shared that she had also experienced abuse and neglect. Similar findings have been reported in other companion animal research, particularly involving adjudicated youth.67 When youth experienced a symbiotic relationship with rescue dogs, many of which were abandoned, abused, and/or neglected, youth were able to identify commonalities with another being. Recognizing these similarities was said to be beneficial, as it provided an avenue for youth to experience insight into themselves, as well as feel unconditional love and respect.[67]
Participants also identified their companion animals as family, in turn prompting a sense of social belonging as well as facilitating their role as a caregiver. Individuals with substance use disorders are often poorly connected to family and established friendships,[40,41] and are frequently disconnected from their role as a caregiver (e.g., loss of custody of children, being the one taken care of).[68,69] These life struggles can continue into their MMT programming. Outside of this study, in a 2015 Harris Poll survey, 95\% of pet owners in the United States reported that they consider pets to be members of the family.[70] The literature also shares that as family members, pets have an important role in resilience; families "value them most at times of crisis and loss, through disruptive transitions, and in weathering prolonged adversity'. [71 p482] Lem and colleagues[36] also found in their study of youth living in homelessness that pet ownership engaged youth in a 'pet before self' mindset, supporting a caretaking role.

\subsection{Theme 2: Health and well-being}

SAMHSA identifies health as the second of four major dimensions that support a life in recovery, defined as 'overcoming or managing one's disease(s) or symptoms-for example, abstaining from use of alcohol, illicit drugs, and nonprescribed medications if one has an addiction problem-and, for everyone in recovery, making informed, healthy choices that support physical and emotional well-being'.[43 p3] Even though well-being is identified in SAMHSA's definition, its prominence in the study data encouraged defining the category more broadly as 'health and well-being'. The term health on its own is most frequently associated with strictly physical wellness. Further, the findings of this study identified a preventative role for companion animals in participants' recovery pathways; they were reported to intuitively respond to individuals' distress and gave participants a reason for their recovery.

Companion animals were perceived to reliably respond to participants' distress with comfort, in turn playing a preventative role in their recovery pathway. SAMHSA's[43] 'health' dimension emphasizes how people can assist an individual in recovery, including the role of peer support and professional services for enhancing health. This is supported in the general recovery literature.[72] However, it is also wellestablished that companion animals, in particular dogs, have the ability to sense emotion-related smells in humans and respond in a supportive way.[73] Most companion animals have not received formal training for this and respond consistently because of informal conditioning and reinforcement.[74] 
This is likewise identified in the animal assisted intervention literature,[75] and more specifically among service animals trained with individuals diagnosed with post-traumatic stress disorder.[76]

Physical contact with an animal can stimulate the release of anti-nociceptive hormones and neurochemicals (e.g., prolactin, dopamine).[28-30] These hormones reinforce feelings of attachment, safety, and trust, and can reduce feelings of anxiety and depression.[18,29,30] The comfort that companion animals provide may be particularly beneficial for individuals recovering from opioid use disorder by naturally stimulating the release and binding of endogenous opioids, as well as oxytocin.[28,30] Similarly, playful interactions with animals can decrease stress among humans by instigating relaxation and happiness,[71,77] and can help individuals divert their attention from negative emotions to experiencing a positive interaction with their pet.[78]

Participants also reported that their companion animals gave them a reason for recovery and encouraged a healthier lifestyle, as well as longevity. Likewise, the Life in Recovery from Addiction in Canada study found that companion animals can be an important reason for someone to start and maintain their recovery.[45] The general pet literature also supports the finding that companion animals are health and longevity promoting, especially for seniors' health. For example, pets can motivate physical movement and food intake,[22] and even reduce the need for health care service use among the elderly. [79] Other literature reports that following a natural disaster (e.g., hurricane), companion animals can enhance chance of survival as they can be important in building resiliency. For example, attachment to companion animals can serve as a motivation to prepare and act (e.g., to seek shelter).[80]

\subsection{Theme 3: Home}

SAMHSA's third dimension to support a life in recovery is home, that is, 'a stable and safe place to live'.[43 p3] The current study reinforced this understanding, with added emphasis on protection, safety, and stability.

Companion animals were found to provide a sense of physical protection and safety to participants, which decreased individuals' stress and anxiety and offered them peace of mind. This was both in the home and extended to public spaces. The lives and circumstances of individuals involved in substance use are often highly chaotic, and oftentimes dangerous if linked to poverty and crime. This does not necessarily, or immediately disappear when an individual starts an MMT program. Supporting this, companion animals are identified in the literature as having a protective role within families, and specifically among homeless populations.[81] Similarly, service dogs are known to reduce stress and anxiety among individuals suffering from post-traumatic stress disorder by 'watching the back' of their handler.[76] This may be particularly beneficial for individuals in recovery from a substance use disorder, as decreased stress can assist with preventing relapse.[82]

It was also found that companion animals contributed to feelings of stability, as participants could depend on coming home to them, although nearly all participants worried about the welfare of their companion animals. As discussed, opioid use disorder and its continued impacts during recovery can be associated with an unstable lifestyle (e.g., unemployment). Companion animals generally add routine to an individual's life.[22] In fact, a recent study found companion animals to be associated with decreased use of housing and employment services because of the stability that animals contributed to individuals' lives.83 Lem et al.[36] specifically found that among youth living in homelessness, locating a safe place for companion animals to live was a priority. Bender, Thompson, McManus, Lantry, and Flynn[84] also concluded that the responsibility of protecting one's pet encouraged youth living in homelessness to continue trying to meet their own basic personal needs.

\subsection{Theme 4: Purpose and empowerment}

SAMHSA's fourth and final dimension of recovery is purpose, defined as 'meaningful daily activities, such as a job, school, volunteerism, family caretaking, or creative endeavors, and the independence, income, and resources to participate in society'.[43 p3] In the current study, companion animals not only gave participants a purpose, they also helped participants to feel empowered.

Participants expressed satisfaction, and possibly pride, in the responsibility they showed by allocating a portion of their earnings to care for their companion animals. This is likewise found in the experiences of individuals living in homelessness while also being pet owners.[37] As shared, finances can be a challenge for individuals with a substance use disorder, specifically the financial costs associated with opioids and other substances. Once again, the impacts can continue into recovery. According to SAMHSA,[43] a feeling of pride can assist an individual with perceiving control over their life, including self-control, thereby positioning recovery as more attainable. In a study of a dog working with a recovery group, it was found that the dog facilitated an increase in self-esteem, and in turn, this 'improved self-image allowed volunteers [in the 
study] a greater understanding of their recovery process'.[85 p31] A similar study at an inpatient addictions centre offering animal assisted therapy found that positive interactions with animals increased individuals' self-awareness.[86]

Passionate stories of animal activism also emerged in this study, which appeared to permit a sense of empowerment and self-identity as the 'rescuer', rather than the one being 'rescued'. Fifty percent of respondents in the Life in Recovery in Canada survey identified 'being worried about what other people would think of you' as a barrier to their recovery.[45] This is explained by Best et al., who say that 'recovery is best understood as a personal journey of socially negotiated identity transition that occurs through changes in social networks and related meaningful activities'.[87 p111] Supporting this, animal assisted intervention programs with inmates who train shelter dogs, including inmates with a substance use disorder, have been successful because of the opportunity to assist with 'rescuing' the other.[88-90] This finding is particularly significant because employment and/or volunteer work is difficult for MMT patients to secure, largely because of their status in a methadone program, and some are not able to commit yet on a daily basis (e.g., physiological reasons). This offers an alternative route for promoting a sense of purpose and empowerment in individuals.

\subsection{Limitations}

There are several key limitations of this study. First, the findings may not be easily applied elsewhere because of the exploratory nature of the study, its specific setting, and limited sample size. Second, there was little attention paid in the interviews to the challenges posed by pets. This was at least partly due to a sampling bias; it did not seem that MMT patients who did not have close relationships with companion animals participated. Third, diversity amongst the participants was neglected. For example, the Canadian Life in Recovery from Addiction Survey found that females were more likely to identify a supportive relationship with animals or pets compared to males (76.2\% and $66.8 \%$, respectively).[72] It is also established that men suffering from an opioid use disorder are more likely to be treated more harshly by health care providers, due in part to the influence of hegemonic standards of masculinity.[91,92]

Likewise, the potential impacts of colonization, as well as the role of animals in Indigenous understandings of well-being were not explored. For example, salient to an Indigenous perspective of well-being is 'one's connection to language, land, beings of creation, and ancestry, supported by a caring family and environment'.[93] Diversity among species of pets could have also been accounted for (e.g., heightened sensory system of canines in comparison to felines to detect emotions). Lastly, to help ensure accurate interpretation of the data, study findings were reviewed by staff of the OARS program clinic for additional feedback and context, but not by patients. It would have been ideal to reconnect with the original study participants, but due to scheduling challenges this was not possible.

\subsection{Future research}

There is a general need for more robust research on the human-animal bond, companion animals, and animal assisted interventions specific to opioid and other substance use disorders.[47-51] Based on the findings of this exploratory study, there are four suggestions for future research. First, it would be insightful to explore treatment providers' perceptions of how companion animals contribute to recovery, as well as their potential role in service provision. This could range from exploring the role of patients' pets in the family system through to including them in therapy sessions.[71] Once again, attention should be paid to the species of pet.

Second, it would be useful to explore the stress individuals experience regarding the welfare of their pets and other animals. Many participants suggested the need for an animal service that is accessible and affordable in their neighbourhood. For example, future research could confirm this on a broader scale, and investigate the potential of implementing an animal shelter in the community with an associated evaluation, as it could provide an avenue for employment and volunteer work for individuals with opioid or other substance use disorders. There are models in Canada (e.g., Community Veterinary Outreach Program) and the United Kingdom (e.g., Blue Cross) to learn from.

Third, other frameworks could have offered strong theoretical grounds to explore this study's findings as well. For example, a One Health perspective, which involves improving the health of humans, animals, and the environment equally, could have been utilized.[94,95] Other potentially noteworthy frameworks include social ecology and an Indigenous worldview.[96] In future studies this could be done in tandem with emerging understanding regarding the impact of disconnection in the lives of individuals who problematically use substances. $[40,41]$

Lastly, there must be greater attention to animal welfare in future studies. It is important that companion animals are not 'instrumentalized' as a health intervention without equal regard for their own well-being. Methodologies developed 
for multispecies ethnographic research could potentially overcome this anthropocentric bias and yield more surprising and significant results.

\section{Conclusions}

Findings from this study offer increasing support for the role of companion animals in individuals' recovery pathways from substance use disorders, particularly opioid dependency. The primary themes of this study aligned with and expanded upon SAMHSA's four dimensions of recovery, introducing how companion animals are a complementary and unique form of support. Overall, individuals' relationships with their companion animals fulfilled supportive roles other humans could not or chose not to provide. The human-animal bond also encouraged a strengths-based approach to individuals' recovery from opioid use disorder. This, in turn, influenced a positive self-identity in individuals and a perceived choice over their recovery pathway. As such, this paper offers a broadened understanding of what constitutes support in recovery, with the inclusion of companion animals.

\section{References}

1.Special Advisory Committee on the Epidemic of Opioid Overdoses. National Report: Apparent Opioid-Related Deaths in Canada (January 2016 to June 2018). Ottawa, ON: Public Health Agency of Canada; April 2019. Available from https:// infobase.phac-aspc.gc.ca/datalab/national-surveillanceopioid-mortality.htmI\#AORD Accessed 7 May 2019.

2.National Institute on Drug Abuse. Misuse of Prescription Drugs. 2018. Available from: https://www.drugabuse.gov/ publications/research-reports/misuse-prescription-drugs/ summary. Accessed 14 September 2018.

3.Inciardi J, Surratt H, Lugo Y, Cicero T. The diversion of prescription opioid analgesics. Law Enforcement Executive Forum 2007; 7(7): 127-141. Available from: https://www. ncbi.nlm.nih.gov/pmc/articles/PMC4176900/. Accessed 15 September 2018.

4.Special Advisory Committee on the Epidemic of Opioid Overdoes. National Report: Apparent Opioid-Related Deaths in Canada (December 2017). Ottawa ON: Public Health Agency of Canada; 2017. Available from: https://www.canada.ca/en/ public-health/services/publications/healthy-living/apparentopioid-related-deaths-report-2016-2017-december.html. Accessed 15 January 2018.

5.Tyndall M. An emergency response to the opioid overdose crisis in Canada: a regulated opioid distribution program. Canadian Medical Association Journal 2018; 190(2): E35-E36. doi: $10.1503 /$ cmaj.171060

6.Canadian Institute for Health Information. Opioid-Related Harms in Canada. Ottawa ON: ClHI; 2017. Available from: https://secure.cihi.ca/free_products/opioid-harms-chartbook-en.pdf. Accessed 15 January 2018.

7.Bothorel T. Fentanyl-laced drugs suspected as cause of nine overdoses at Saskatoon jail in two weeks. CBC News. 23 November 2018. Available from: https://www.cbc.ca/ news/canada/saskatoon/saskatoon-jail-drug-overdosefentanyl-1.4918207 Accessed 23 March 2019.

8. Health Canada. Methadone program. 27 April 2017. Available from: https://www.canada.ca/en/health-canada/ services/health-concerns/controlled-substances-precursorchemicals/exemptions/methadone-program.html Accessed 21 March 2019.

9.College of Physicians and Surgeons of Saskatchewan. Methadone guidelines and standards for the treatment of opioid addiction/dependence. Saskatoon SK: College of Physicians and Surgeons of Saskatchewan; 2015. Available from: http://www.cps.sk.ca/imis/Documents/Programs $\% 20$ and\%20Services/Methadone/SK-Methadone-Guidelines2015-Mar-FINAL.pdf. Accessed 15 August 2018.

10.Pickett N, Domene J. Counselling utilization experiences among methadone maintenance treatment clients in rural and small urban communities. Canadian Journal of Counselling and Psychotherapy 2014; 48(1): 22-37. Available from: https://cjc-rcc.ucalgary.ca. Accessed 1 September 2018.

11.Thomas G. Harm Reduction Policies and Programs for Persons Involved in the Criminal Justice System. Ottawa ON: Canadian Centre on Substance Abuse; 2005. 12 p. Available from http://www.ccsa.ca/Resource\%20Library/ccsa-0039002005.pdf. Accessed 25 September 2018.

12.Vigilant LG. The stigma paradox in methadone maintenance: naïve and positive consequences of a "treatment punishment" approach to opiate addiction. Humanity \& Society 2004; 28(4): 403-418. https://doi.org/1 $0.1177 \% 2 F 016059760402800404$

13. Erdelyan M, Young C. Methadone Maintenance Treatment: A Community Planning Guide. Toronto, ON: Centre for Addiction and Mental Health, 2009.

14.Anderson-Baron J, Karekezi K, Koziel J, McCurdy A. Saskatchewan Policy Analysis Case Report. Edmonton AB: CHARPP; 2017. 41 p. Available from: https://crismprairies.ca/ wp-content/uploads/2018/06/Saskatchewan.pdf. Accessed 28 August 2018. 
15. da Silveira PS, de Tostes JG, Wan HT, Ronzani TM, Corrigan PW. Chapter 2: The stigmatization of drug use as mechanism of legitimation of exclusion. In: Ronzani T. (eds) Drugs and Social Context 2018; 15-25. Springer, Cham.

16.Smye V, Browne AJ, Varcoe C, Josewski V. Harm reduction, methadone maintenance treatment and the root causes of health and social inequities: An intersectional lens in the Canadian context. Harm Reduction Journal Dec 2011; 8(1):17. doi: 10.1186/1477-7517-8-17

17.Brands B, Marsh D, Hart L, Jamieson W. Best PracticesMethadone Maintenance Treatment. Ottawa ON: Health Canada; 2002. 94 p. Available from: http://publications. gc.ca/collections/collection_2012/sc-hc/H49-162-2002eng.pdf. Accessed 23 March 2018.

18.Schindler A, Thomasius R, Petersen K, Sack PM. Heroin as an attachment substitute? Differences in attachment representations between opioid, ecstasy and cannabis abusers. Attachment \& Human Development 2009; 11(3): 307-330. doi: 10.1080/14616730902815009

19.Young KA, Gobrogge KL, Wang Z. The role of mesocorticolimbic dopamine in regulating interactions between drugs of abuse and social behavior. Neuroscience \& Biobehavioral Reviews 2011; 35(3): 498-515. doi: 10.1016/j. neubiorev.2010.06.004

20.CATIE. People living with HIV in Canada. 2018. Available from: http://librarypdf.catie.ca/PDF/ATI-40000s/40239_B. pdf. Accessed 23 March 2019.

21.Challacombe L. The epidemiology of HIV in people who inject drugs in Canada. CATIE; 2018. Available from: https:// www.theglobeandmail.com/canada/article-newly-diagnosedhiv-cases-in-saskatchewan-increase-for-third-straight-2/. Accessed 23 March 2019.

22. Hodgson K, Barton L, Darling M, Antao V, Kim FA, Monavvari A. Pets' impact on your patients' health: leveraging benefits and mitigating risk. The Journal of the American Board of Family Medicine 2015; 28(4): 526-534. doi: 10.3122/ jabfm.2015.04.140254

23.Alberta Ministry of Agriculture and Rural Development. Consumer Corner: Canadian Pet Market Outlook, 2014. Edmonton AB: Alberta Agriculture and Forestry; 2014. Available from: http://www1.agric.gov.ab.ca/\$department/ deptdocs.nsf/all/sis14914. Accessed 12 February 2018.

24.McNicholas J, Collins GM. Animals as social supports: insights for understanding animal-assisted therapy. In: Fine A (ed.). Handbook on Animal-Assisted Therapy: Theoretical
Foundations and Guidelines for Practice. 2nd ed. San Diego CA: Elsevier, 2006: 49-72.

25.Sable P. Pets, attachment, and well-being across the life cycle. Social Work 1995; 40(3): 334-341. https://doi. org/10.1093/sw/40.3.334

26.Wood L, Giles-Corti B, Bulsara M. The pet connection: pets as a conduit for social capital? Social Science \& Medicine 2005 61(6): 1159-1173. doi: 10.1016/j.socscimed.2005.01.017

27.Friedmann E, Thomas S, Eddy T. Companion animals and human health: physical and cardiovascular influences. In: Podberscek A, Paul E, Serpell J (eds). Companion Animals and Us: Exploring the Relationships Between People and Pets. Cambridge UK: Cambridge University Press, 2000; 125-142.

28. Handlin L, Hydbring-Sandberg E, Nilsson A, Ejdeback M, Jansson A, Uvnas-Moberg K. Short-term interaction between dogs and their owners: effects of oxytocin, cortisol, insulin and heart rate. Anthrozoos 2011; 24(3): 301-315. doi:10.2752/1 $75303711 \times 13045914865385$.

29.Matuszek S. Animal-facilitated therapy in various patient populations: Systematic literature review. Holistic Nursing Practice 2010; 24(4): 187-203. doi: 10.1097/ HNP.0b013e3181e90197

30. Miller SC, Kennedy C, DeVoe D, Hickey M, Nelson T, Kogan L. An examination of changes in oxytocin levels in men and women before and after interaction with a bonded dog. Anthrozoos 2009; 22(1): 31-42. doi:10.2752/175303708X390455

31.Wu AS, Niedra R, Pendergast L, McCrindle BW. Acceptability and impact of pet visitation on a pediatric cardiology inpatient unit. Journal of Pediatric Nursing 2002; 17(5): 354-362. doi:10.1053/jpdn.2002.127173

32. Motomura N, Yagi T, Ohyama H. Animal assisted therapy for people with dementia. Psychogeriatrics 2004; 4(2): 40-42. https://doi.org/10.1111/j.1479-8301.2004.00062.x

33.Walsh PG, Mertin PG, Verlander DF, Pollard CF. The effects of a 'pets as therapy' dog on persons with dementia in a psychiatric ward. Australian Occupational Therapy Journal 1995; 42(4): 161-166.https://doi.org/10.1111/j.1440-1630.1995 tb01331.x

34.Wisdom JP, Saedi GA, Green CA. Another breed of "service" animals: STARS study findings about pet ownership and recovery from serious mental illness. American Journal of Orthopsychiatry 2009; 79(3): 430. doi: 10.1037/a0016812

35.Zisselman MH, Rovner BW, Shmuely Y, Ferrie P. A pet therapy intervention with geriatric psychiatry inpatients. The 
American Journal of Occupational Therapy 1996; 50(1): 4751. doi: 10.5014/ajot.50.1.47

36.Lem M, Coe JB, Haley DB, Stone E. Effects of companion animal ownership among Canadian street-involved youth: a qualitative analysis. Journal of Sociology and Social Welfare 2013; 40: 285. Available from: https://scholarworks.wmich. edu/jssw/vol40/iss4/15. Accessed 2 October 2017.

37.Irvine L. Animals as lifechangers and lifesavers: Pets in the redemption narratives of homeless people. Journal of Contemporary Ethnography 2013; 42(1): 3-30. doi: 10.1177/0891241612456550

38.Klemetsen MG, Lindstrøm TC. Animal-assisted therapy in the treatment of substance use disorders: a systematic mixed methods review. Human-Animal Interaction Bulletin 2017; 5(2): 90-117. Available from: https://bergensklinikkene.com/ wp-content/uploads/2017/10/Animal-Assisted-Therapyin-the-Treatment-of-Substance-Use-Disorders-Man041016proofs.pdf. Accessed 2 September 2018.

39. Anna-Belle the Therapy Dog, with the assistance of Dell CA, Sewap G, McAllister B, Bachiu J. "She makes me feel comfortable": Understanding the impacts of animal assisted therapy at a methadone clinic". Journal of Indigenous HIV Research 2018; 9: 57-65. Available from: http://www. ahacentre.ca/volume-9.html Accessed 24 March 2019.

40.Maté G. In the Realm of Hungry Ghosts: Close Encounters with Addictions. Toronto ON: Random House of Canada, 2009.

41.Weiss R. The opposite of addiction is connection. Psychology Today. 30 September 2015. Available from: https://www.psychologytoday.com/ca/blog/love-and-sex-inthe-digital-age/201509/the-opposite-addiction-is-connection. Accessed 15 August 2018.

42. Terpin JL. Exploring the human-animal bond in an animalassisted therapy program for at-risk youth [unpublished dissertation]. Keene $\mathrm{NH}$ : Antioch New England Graduate School; 2004. Available from: https://habricentral.org/ resources/39013 Accessed 18 September 2018.

43.Substance Abuse and Mental Health Services Administration. SAMHSA's Working Definition of Recovery: 10 Guiding Principles of Recovery. Rockville, MD: SAMHSA; 2012. 8 p. Available from: https://store.samhsa.gov/shin/content/ PEP12-RECDEF/PEP12-RECDEF.pdf. Accessed 19 June 2018.

44.Canadian Centre on Substance Use and Addiction. National Commitment to Recovery. Ottawa ON: CCSA; 2018. Available from: http://www.ccdus.ca/Resource\%20Library/ CCSA-National-Summit-Addiction-Recovery-Backgrounder- 2015-en.pdf. Accessed 5 March 2018.

45.McQuaid R, Malik A, Moussouni AK, Baydack N, Stargardter M, Morrisey M. Life in Recovery from Addiction in Canada. Ottawa ON: Canadian Centre on Substance Abuse and Addiction; 2017. 84 p. Available from: http://www.ccsa.ca/ Resource\%20Library/CCSA-Life-in-Recovery-from-AddictionReport-2017-en.pdf. Accessed 3 October 2017.

46. Bachi K. Equine-facilitated prison-based programs within the context of prison-based animal programs: State of the science review. Journal of Offender Rehabilitation 2013; 52(1): 46-74. doi: 10.1080/10509674.2012.734371

47.Bert F, Gualano MR, Camussi E, Pieve G, Voglino G, Siliquini R. Animal assisted intervention: a systematic review of benefits and risks. European Journal of Integrative Medicine 2016; 8(5): 695-706. https://doi.org/10.1016/j.eujim.2016.05.005

48.Cooke BJ, Farrington DP. The effectiveness of dog-training programs in prisons: a systematic review and meta-analysis of the literature. The Prison Journal 2016; 96(6): 854-876. https://doi.org/10.1177/0032885516671919

49.Morrison ML. Health benefits of animal-assisted interventions. Complementary Health Practice Review 2007; 12(1): 51-62. https://doi.org/10.1177/1533210107302397

50.0'Haire M. Companion animals and human health: Benefits, challenges, and the road ahead. Journal of Veterinary Behavior: Clinical Applications and Research 2010; 5(5): 226234. https://doi.org/10.1016/j.jveb.2010.02.002

51.Craig M, Giles D. Suboxone added to Saskatchewan's drug plan coverage. Global News. 27 January 2017. Available from: https://globalnews.ca/news/3210279/suboxone-added-tosaskatchewans-drug-plan-coverage/. Accessed 26 September 2018.

52. Hagaman AK, Wutich A. How many interviews are enough to identify metathemes in multisited and cross-cultural research? Another perspective on Guest, Bunce, and Johnson's (2006) landmark study. Field Methods 2017; 29(1): 23-41. https:// doi.org/10.1177/1525822X16640447

53.American Psychiatric Association. Diagnostic and Statistical Manual of Mental Disorders (DSM-5). Arlington VA: American Psychiatric Publishing, 2013.

54.Thraves BD, editor. Saskatchewan: Geographic Perspectives (No. 52). Regina SK: University of Regina Press, 2008. Available from: http://pcag.uwinnipeg.ca/PrairiePerspectives/PP-Vol11/PP_Vol-11.pdf. Accessed 17 March 2018. 
55.Kitchen P, Williams A. Quality of life and perceptions of crime in Saskatoon, Canada. Social Indicators Research 2010; 95(1): 33-61. doi: 10.1007/s11205-009-9449-2

56. Hamilton C. How 1 block in Saskatoon provides a snapshot of the city's evolving west side. CBC Saskatoon.14 September 2017. Available from: https://www.cbc.ca/news/ canada/saskatoon/600-block-avenue-h-saskatoon-inner-citygentrification-1.4285444. Accessed 19 August 2018.

57.Creswell J, Creswell J. Research Design: Qualitative, Quantitative, and Mixed Methods Approaches. 5th ed. Los Angeles CA: Sage, 2018.

58.Kirby S, Greaves L, Reid C. Experience, Research, Social Change: Methods Beyond the Mainstream. 2nd ed. Peterborough ON: Broadview Press, 2006.

59.Starks H, Brown Trinidad S. Choose your method: a comparison of phenomenology, discourse analysis, and grounded theory. Qualitative Health Research 2007; 17(10): 1372-1380. doi:10.1177/1049732307307031

60.Braun V, Clarke V. Using thematic analysis in psychology. Qualitative Research in Psychology 2006; 3(2): 77-101. doi: 10.1191/1478088706qp063oa

61.Centre for Innovation in Research \& Teaching. Phenomenology Methods \& Data Collection. 2018. Available from: https://cirt.gcu.edu/research/developmentresources/ research_ready/phenomenology/methods_data. Accessed 24 August 2018.

62.Thege BK, Colman I, el-Guebaly N, et al. Social judgments of behavioral versus substance-related addictions: a populationbased study. Addictive Behaviors 2015; 42: 24-31. https:// doi.org/10.1016/j.addbeh.2014.10.025

63. Barnet R. Addict in the House: A No-Nonsense Family Guide Through Addiction \& Recovery. Oakland CA: New Harbinger Publications Inc, 2013.

64.Beck L, Madresh EA. Romantic partners and fourlegged friends: an extension of attachment theory to relationships with pets. Anthrozoös 2008; 21(1): 43-56. doi: 10.2752/089279308X274056

65.Kanat-Maymon Y, Antebi A, Zilcha-Mano S. Basic psychological need fulfillment in human-pet relationships and well-being. Personality and Individual Differences 2016; 92: 69-73. doi: 10.1016/j.paid.2015.12.025

66.Wozniak EP. Addiction recovery and animal companionship [unpublished dissertation]. Minneapolis MN: Walden University; 2014. Available from: https://search.proquest. com/openview/08f9630779d3ea1f68bdcef065021e12/ 1 ?pq-origsite $=$ gscholar \&cbl=18750\&diss $=y . \quad$ Accessed 18 September 2018.

67.Johnson A, Bruneau L. Healing bonds: Animal assisted interventions with adjudicated male youth. In: Blazina, C, Kogan, LR (eds). Men and Their Dogs. Springer, 2016; 113 132.

68.Niccols J, Dell C, Clarke S. Treatment for Aboriginal mothers with substance use problems and their children: invited submission for special issue on violence, mental health, and addiction issues facing Aboriginal populations. International Journal of Mental Health and Addiction 2010; 8(2): 320-335. https://doi.org/10.1007/s11469-009-9255-8

69.Poole N. Aurora Centre Annual Newsletter on 2002 Activities and Evaluation Results. Vancouver BC: Aurora Centre, BC Women's Hospital, 2003.

70.The Harris Poll. More Than Ever, Pets are Members of the Family. 2015. Available from: https://theharrispoll.com/ whether-furry-feathered-or-flippers-a-flapping-americanscontinue-to-display-close-relationships-with-their-pets-2015is-expected-to-continue-the-pet-industrys-more-than-twodecades-strong/. Accessed 1 September 2018.

71.Walsh F. Human-animal bond II: the role of pets in family systems and family therapy. Family Process 2009; 48(4): 481499. https://doi.org/10.1111/j.1545-5300.2009.01297.x

72.McQuaid R, Dell C. Life in recovery from addiction in Canada: Examining gender pathways with a focus on the female experience. Alcoholism Treatment Quarterly 2018; 1-18. doi: 10.1080/07347324.2018.1502642

73.Swanson L. Smile! And Other Practical Life Lessons Your Dogs Can Teach You (While You are Training Them). La Vergne TN: Ingram Publishing, 2016.

74.Udell MA, Wynne CD. A review of domestic dogs' (Canis Familiaris) human $\square$ like behaviors: or why behavior analysts should stop worrying and love their dogs. Journal of the Experimental Analysis of Behavior 2008; 89(2): 247-261. doi:10.1901/jeab.2008.89-247

75.Chandler CK. Animal-Assisted Therapy in Counseling. 2nd ed. New York: Taylor \& Francis, 2017.

76.Taylor MF, Edwards ME, Pooley JA. "Nudging them back to reality": Toward a growing public acceptance of the role dogs fulfill in ameliorating contemporary veterans' PTSD symptoms. Anthrozoös 2013; 26(4): 593-611. doi: 10.2752/175303713 X13795775535896 
77.Marcus DA, Blazek-O'Neill B, Kopar JL. Symptom reduction identified after offering animal-assisted activity at a cancer infusion center. American Journal of Hospice and Palliative Medicine 2014; 31(4): 420-421. doi: 10.1177/1049909112469275.

78.Odendaal J, Lehmann S. The role of phenylethylamine during positive human-dog interaction. Acta Veterinaria Scandinavica 2000; 69(3): 183-3. https://doi.org/10.2754/ avb200069030183

79.Siegel JM. Stressful life events and use of physician services among the elderly: the moderating role of pet ownership. Journal of Personality and Social Psychology 1990; 58(6): 1081. doi: 10.1037/0022-3514.58.6.1081

80.Thompson K, Every D, Rainbird S, Cornell V, Smith B, Trigg J. No pet or their person left behind: Increasing the disaster resilience of vulnerable groups through animal attachment, activities and networks. Animals 2014; 4(2):214-40. doi:10.3390/ani4020214

81.Irvine L. My Dog Always Eats First: Homeless People and Their Animals. Sterling VA: Kumarian Press, 2013.

82.NIDA. Stressful Experiences Affect Likelihood of Remission of Drug Dependence, Continued Drug Use, and Relapse. 2018. Available from: https://www.drugabuse.gov/news-events/ nida-notes/2018/02/stressful-experiences-affect-likelihoodremission-drug-dependence-continued-drug-use-relapse. Accessed 3 April 2018.

83. Rhoades $\mathrm{H}$, Winetrobe $\mathrm{H}$, Rice E. Pet ownership among homeless youth: associations with mental health, service utilization and housing status. Child Psychiatry \& Human Development 2015; 46(2): 237-244. doi: 10.1007/s10578014-0463-5

84.Bender K, Thompson SJ, McManus H, Lantry J, Flynn PM. Capacity for survival: Exploring strengths of homeless street youth. Child and Youth Care Forum 2007; 36(1): 25-42. doi:10.1007/s10566-006-9029-4

85.Campbell-Begg T. A case study using animalassisted therapy to promote abstinence in a group of individuals who are recovering from chemical addictions. Journal of Addictions Nursing 2000; 12(1): 31-35. doi: 10.3109/10884600009040635

86. Coetzee N, Beukes JT, Lynch I. Substance abuse inpatients' experience of animal-assisted therapy. Journal of Psychology in Africa 2013; 23(3): 477-480. doi: 10.1080/14330237.2013.10820654

87.Best D, Beckwith M, Haslam C, et al. Overcoming alcohol and other drug addiction as a process of social identity transition: the social identity model of recovery (SIMOR). Addiction Research \& Theory 2016; 24(2): 111-123. doi: 10.3109/16066359.2015.1075980

88. Hill L. Becoming the person your dog thinks you are: an assessment of Florida prison-based dog training programs on prison misconduct, post-release employment and recidivism [unpublished dissertation]. Tallahassee FL: Florida State University; 2016. Available from: https://search.proquest. com/openview/62382615a07466fac9d1c662013bc0a0 /1?pq-origsite $=$ gscholar\&cbl=18750\&diss=y. Accessed 25 September 2018.

89.King T. Paws in prison: a second chance [unpublished master's thesis]. Fayetteville AR: University of Arkansas; 2014. Available from: https://scholarworks.uark.edu/etd/2190/. Accessed 15 August 2018.

90.Weaver S. Prison animal training programs: Attachment theory as an explanation for changes in inmate behavior [unpublished dissertation]. Minneapolis: Northcentral University; 2015. Available from: https://search.proquest. com/openview/bd21c5014f7f64e6c17056741d906ed1/ 1?pq-origsite $=$ gscholar $\& \mathrm{cbl}=18750 \&$ diss $=y . \quad$ Accessed 18 August 2018.

91.Gladstone EJ, Smolina K, Morgan SG. Trends and sex differences in prescription opioid deaths in British Columbia, Canada. Injury Prevention 2016; 22(4): 288-290. doi: 10.1136/injuryprev-2015-041604

92.Japaridze E. Drugs, Gender and Stereotypes. Tbilisi GA: Centre for Social Sciences; 2014. 20 p. Available from: http:// css.ge/files/Papers/Drugs,_Gender_and_Stereotypes_2014. pdf. Accessed 22 February 2018.

93.Dumont J, National Native Addictions Partnership Foundation (NNAPF). Definition of Wellness. 2014. Available from: $\quad$ http://www.addictionresearchchair.ca/creatingknowledge/national/honouring-our-strengths-culture-asintervention/growing-wellness-connecting-with-culture/

94.Hodgson K, Darling M. Zooeyia: An essential component of "One Health". The Canadian Veterinary Journal. 2011 Feb; 52(2): 189. Available from: https://www.ncbi.nlm.nih.gov/ pmc/articles/PMC3022463/

95. Hediger K, Meisser A, Zinsstag J. A One Health Research Framework for Animal-Assisted Interventions. International journal of environmental research and public health. 2019 Jan; 16(4): 640. https://doi.org/10.3390/ijerph16040640 96.Chalmers D, Dell CA. Applying one health to the study of 
animal-assisted interventions. EcoHealth 2015 Dec 1; 12(4):

560-2. https://doi.org/10.1007/s10393-015-1042-3

To contact the authors:

Brynn M. Kosteniuk, BA. \& BSC.

University of Saskatchewan

Department of Psychology (Health Studies)

Room 1109-9 Campus Drive

Saskatoon, Saskatchewan, S7N 5A5, Canada

email: brynn.kosteniuk@usask.ca

Colleen Anne Dell, PhD

University of Saskatchewan

Department of Sociology 